\title{
ИНДЕКСЫ УДЕРЖИВАНИЯ ДЛЯ АЛКЕНОВ, АЛКИНОВ И ЦИКЛЕНОВ НА КАПИЛЛЯРНЫХ КОЛОНКАХ
}

Индексы удерживания - лучший критерий для качественных измерений и оценки разделяемых систем в газовой хроматографии. Они зависят только от характеристики жидкой фазы, но некоторое влияние на них оказывает и температура колонки.

В последнее время все больше исследуют зависимость индексов удерживания от температуры $\left[^{1-4}\right]$.

В настоящей работе рассчитаны индексы удерживания для алкенов, алкинов и цикленов на капиллярных колонках с различными жидкими фазами в температурном интервале $30-120^{\circ} \mathrm{C}$.

\section{Экспериментальная часть}

Алкены, алкины, циклопентены и циклогексены, которые применялись для анализов на газовом хроматографе, были синтезированы в нашей лабораторин.

Алкины получены по методу Азингера, Фелла и Стефана [5]. транс-Изомеры $\boldsymbol{H}$-алкенов синтезированы методом парциального гидрирования соответствующих $н$-алкинов на металлическом натрии в жидком аммиаке [5]. Синтез циис-изомеров проведен путем гидрирования $\boldsymbol{H}$-алкинов в присутствии селективно действующего катализатора Линдляра [ $\left.{ }^{6}\right]$.

1-Алкилциклопентены были синтезированы из циклопентанона и соответствующего реактива Гриньяра путем дегидроксилирования образовавшегося 1-алкилциклопентанола иодом [7]. При синтезировании 3-алкилциклопентена применялся метод, в основе которого была реакция 3-хлорциклопентена и соответствующего алкилгалогенида магния.

1-Алкилциклогексены изготовлены из циклогексанона при помощи реактива Гриньяра и затем дегидроксилированы на $\mathrm{CuSO}_{4}$ или $\mathrm{Al}_{2} \mathrm{O}_{3}$, 3-алкилциклогексены изготовлены из циклогексена селективным бромированием бромсукцинимидом в положении 3 и алкнлированы реактивом Гриньяра, а 4-алкилциклогексены - из $н$-алкилфенолов гидрогенизаџией и термическим разложением на $\mathrm{Al}_{2} \mathrm{O}_{3}$ ацетилированных 4-алкилциклогексанолов $[8,9]$. Чистота полученных продуктов проверялась газохроматографически.

Анализ проведен на хроматографе «Хром-2» с пламенно-нонизационным детектором, газ-носитель азот. Давдение газа-носителя на входе в колонку $1,5-1,7 \kappa 2 / \mathrm{cm}^{2}$. Средняя линейная скорость газа-носителя 3-5 м/мин определена как отношение длины колонки ко времени удерживания практически несорбирующегося вещества.

Характеристика капиллярных колонок приведена в табл. 1. 
Характеристика капиллярных колонок

\begin{tabular}{l|l|c|c}
\hline \multicolumn{1}{c|}{ Жидкая фаза } & Материал колонки & $\begin{array}{c}\text { Длина } \\
\text { колонки, } \boldsymbol{M}\end{array}$ & $\begin{array}{c}\text { Внутренний диаметр } \\
\text { колонки, м.м }\end{array}$ \\
\hline Сквалан & Медь & 80 & 0,25 \\
Полифениловый эфир & Нержавеющая сталь & 45 & 0,25 \\
Полиэтиленгликоль 4000 & То же & 80 & 0,25
\end{tabular}

В каждой серии опытов проведены 3-6 параллельных определений. На основании приведенных времен удерживания веществ определены индексы удерживания [10]

$$
I_{T}^{C}=100 z+\frac{\log t s x-\log t s z}{\log t s(z+1)-\log t s z}
$$

где $t s x, t s z, t s(z+1)$ - приведенные времена удерживания анализируемого компонента и $\boldsymbol{H}$-парафинов с числом углеродных атомов в молекулах $z$ и $z+1$.

Средняя квадратичная ошибка при определении индексов удерживания составляла $\pm 0,6$ единиц.

\section{Обсуждение результатов}

Индексы удерживания для алкенов и алкинов рассчитаны на капиллярных колонках с тремя разными жидкими фазами (табл. 2). На рис. 1 приведены хроматограммы, полученные при разделении искусственных смесей алкенов, откуда видно, что полярная жидкая фаза лучше подходит для разделения изомерных алкенов

Индексы удерживания для циклопентенов и циклогексенов, рассчитанные на капиллярных колонках со скваланом и полиэтиленгликолем 4000 , приведены в табл. 3. Как видно из хроматограммы нскусственной смеси (рис. 2) циклогексенов, капиллярная колонка со скваланом успешно разделяет циклены. Частично разделяются только 3- и 4-алкилциклогексены.

Для сравнения полярных жидких фаз со скваланом была рассчитана величнна $\Delta I-$ разница между индексами удержнвания одного вещества на различных жидких фазах (табл. 2, 3).

При сравнении сквалана и полифенилового эфира $\Delta I$ остается в пределах 35-41 единицы для всех изомеров $\boldsymbol{\mu}$-алкенов. При сравнении сквалана и полиэтиленгликоля 4000 можно заметить разницу в величинах $\Delta I$ для разных изомеров. У цис-2-изомеров $\Delta I$ возрастает до $75-76$ единиц, а у транс-3- и -4-изомеров уменьшается до 55-62 единиц. У других изсмеров $\Delta I$ колеблется в пределах 64-67 единиц.

При сравнении индексов удерживания $t$-алкинов на сквалане и полиэтиленгликоле 4000 заметно возрастание $\Delta I$ в ряду 4-, 3-, 2- и 1-изомеров.

Из представленных в табл. 3 значений $\Delta I$ некоторых цикленов на различных жидких фазах следует, что по сравнению с $н$-алкилцикленами разность $\Delta I$ для аллилцикленов особенно велика (200-230 единиц) и несколько меньшая для изоалкилцикленов (110-120 единиц). При срав. нении между собой капиллярных колонок с полиэтиленгликолем 4000 і 

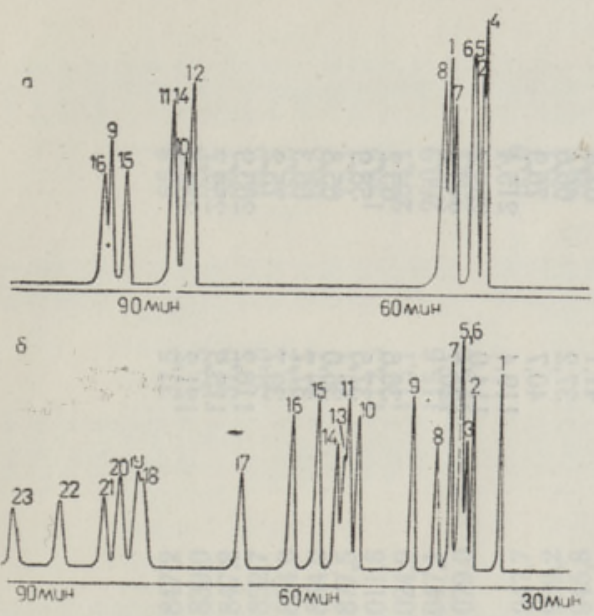

Рис. 1. Хроматограмма $\boldsymbol{H}$-алкенов. $a$ - капиллярная колонка со скваланом, температура колонки $79^{\circ} \mathrm{C}$, входное давление $1,48 \kappa 2 / \mathrm{cm}^{2} ; \sigma-$ капиллярная колонка с полиэтиленгликолем 4000, температура колонки $73^{\circ}$, входное давление

$$
1,8 \mathrm{~K} 2 / \mathrm{cm} \mathrm{M}^{2} \text {. }
$$

1 - н-октан, 2 - транс-октен-4, 3 - транс-ок тен-3, 4 - октен-1, $5-$ цис-октен-4, $6-$ иисоктен-3, 7 - траћс-октен-2, 8 - цис-октен-2, 9 н-нонан, 10 - транс-нонен-4, 11 - транс-нонен-5, 12 - нонен-1, 13 - цис-нонен-4, $14-$ чис-нонен-3. 15 - транс-нонен-2, 16 - цис-нонен-2, $17-$-н-декан, 18 - транс-децен-4, 19 - транс-децен-5, 20 транс-децен-3, 21 - чис-децен-3, 22 - транс-де иен-2, 23 - цис-децен-2.

Рнс. 3. Зависимость индексов удерживания алкенов, алкинов и цикленов от числа углеродных атомов в молекуле на капил лярной колонке с полиэтиленгликолем 4000.

$t$ - алкин-2, 2 - алкин-1, 3 - алкин-3, 4 1-алкилциклогексен-1, 5 - 3-алкилциклогек:ен-1, 6 - 1-алкилциклопентен-1, 7 - 3-алкил ииклопентен-1, 8 - цис-алкен-2, 9 - транс алкен-2, $10-u и c$-алкен-3, $11-$ алкен-1, $12-$ транс-алкен-3, 13 - транс-алкен-4.

скваланом полученная разность $\Delta I$

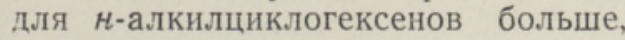
чем для $\boldsymbol{H}$-алкилциклопентенов.

На рис. 3 приведены графики зависнмости индексов удерживания для алкенов, алкинов и цикленов от числа углеродных атомов в молекуле на капиллярной колонке с полиэтиленгликолем 4000 . Линейная зависимость действительна для всех групп углеводородов в пределах числа углеродных атомов $\mathrm{C}_{6}-\mathrm{C}_{12}$.

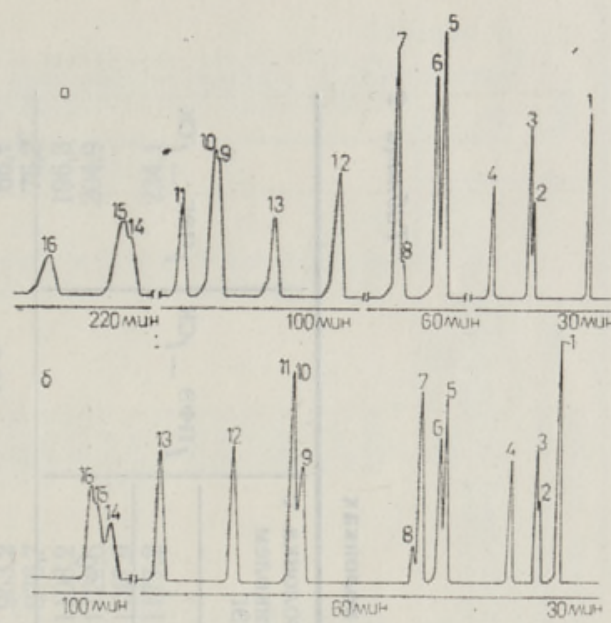

Рис. 2. Хроматограмма циклогексенов. $a$ - жидкая фаза - сквалан, температура колонки $81^{\circ} \mathrm{C}$, входное давление 1,51 ка/см ${ }^{2}$, $\sigma$ - жидкая фаза - полиэтиленгликоль 4000 , температура колонки $82^{\circ}$, входное давление $1,73 \mathrm{\kappa} / \mathrm{cm}^{2}$.

1 - циклогексен, 2 - 3-метилциклогексен-1, 3 4-метилциклогексен-1, 4-метициклогексен-1, 35 - 3-этилциклогексен-1, $6-4$-этилцнклогексен-1, 7 - 1-этилциклогексен-1, 8 - прнмесь в 1-этнлциклогексене-1, 9 - 3-пропилциклогексен-1, 10 - 4-пропилциклогексен-1, 11 - 1-пропилциклогексен-1, 12 - 3-аллилщиклогексен-1, 13 - 1-ал-

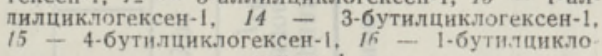
гексен-1.

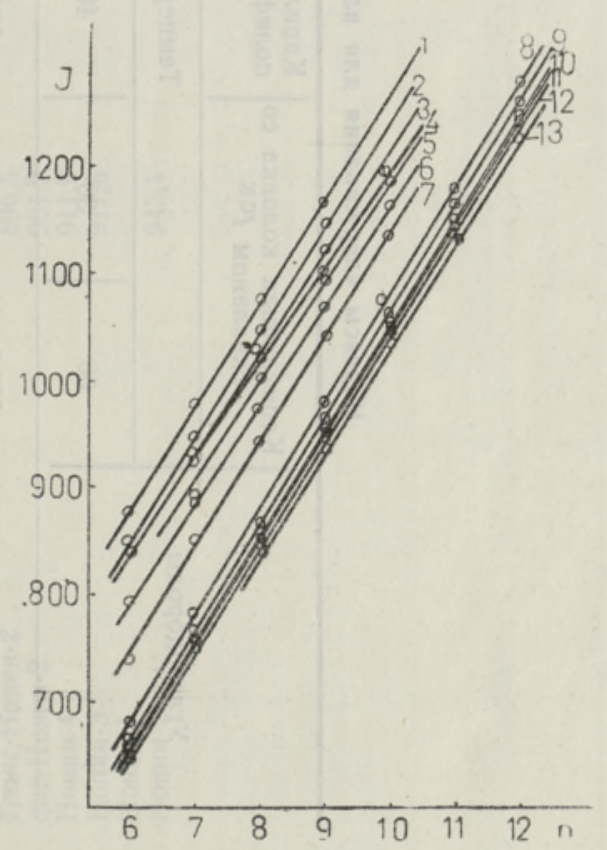

В табл. 2, 4 представлены температурные зависимости индексов удер- 


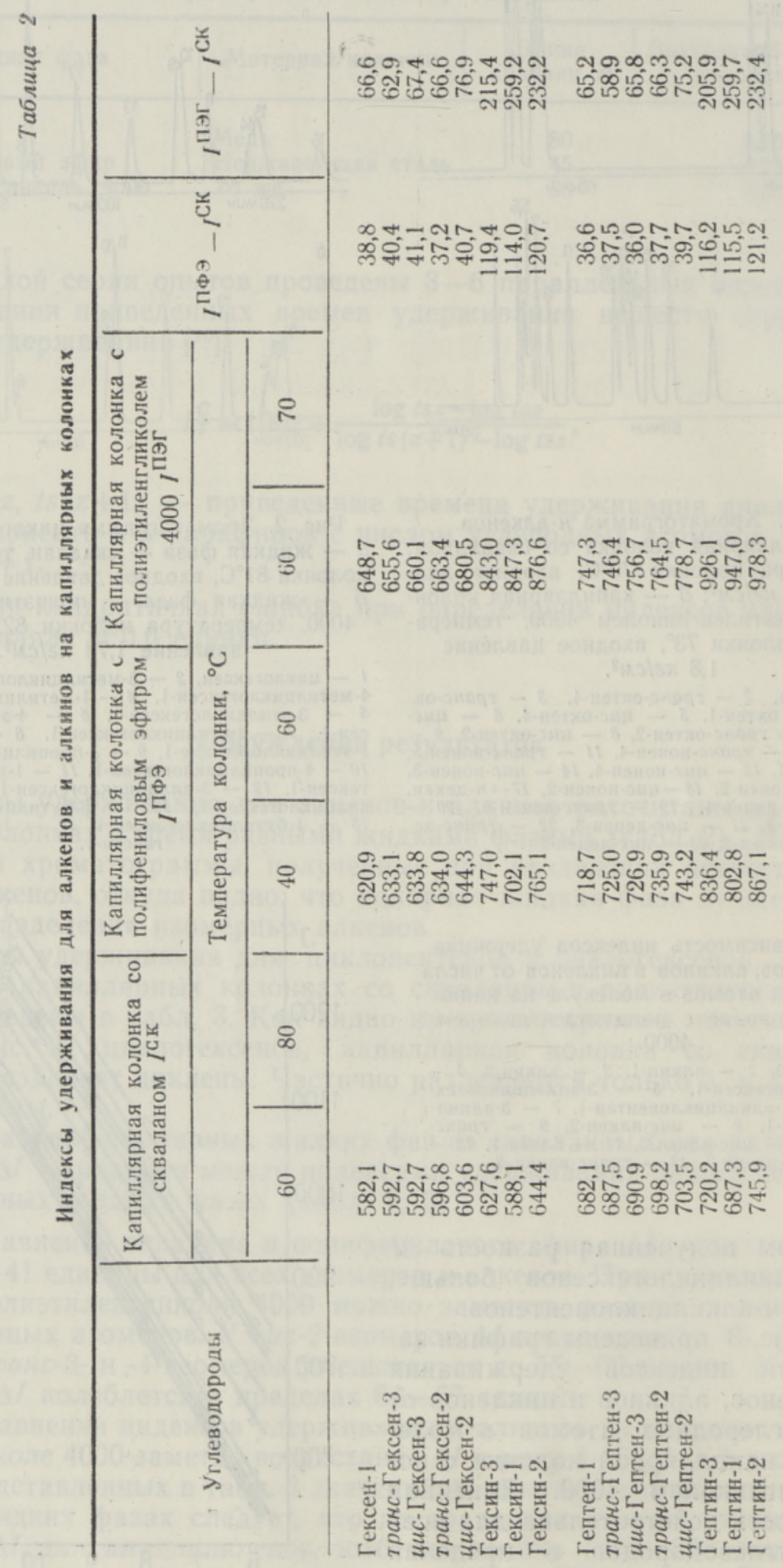




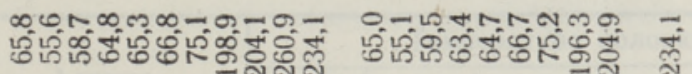

กอ 0.0 .

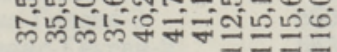

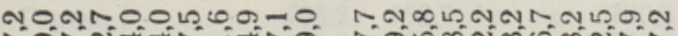

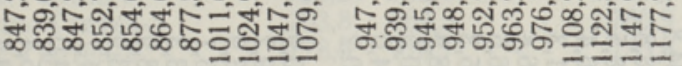

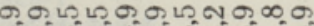

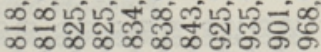

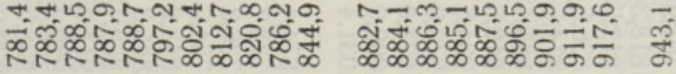

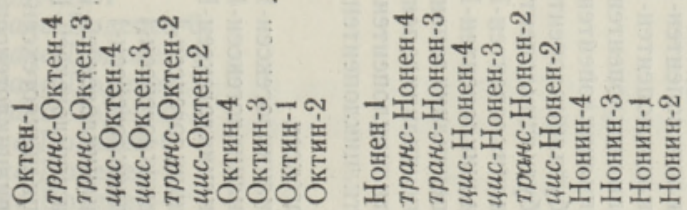




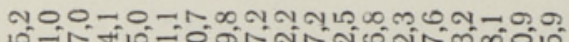

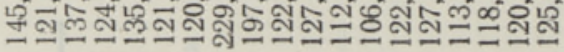

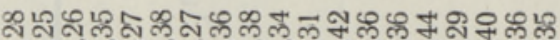
000000000000000

$+\infty$ ด

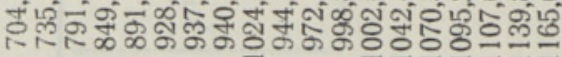

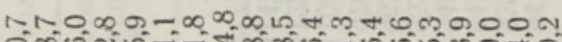

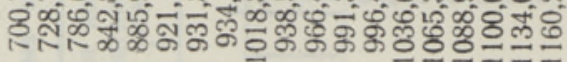

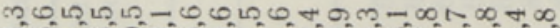

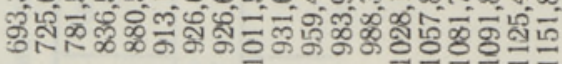

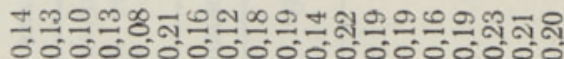
(1)

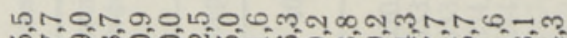

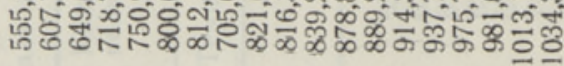

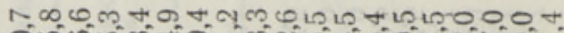

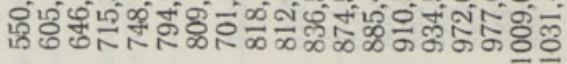

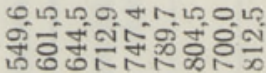

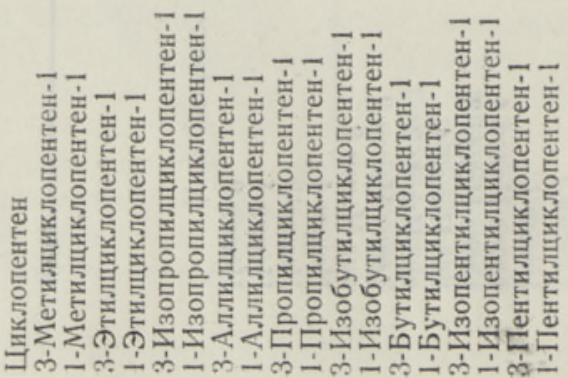

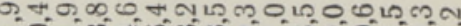

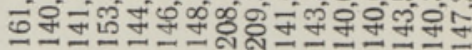

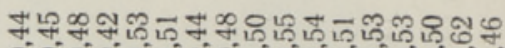

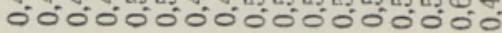

$\mathrm{T}=\mathrm{O}-\mathrm{N} N \mathrm{~N}=0,0000 \%$

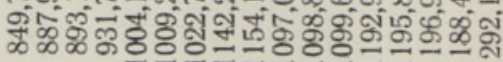

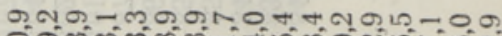
চळळ

HOOMNOMNNOOMOL-

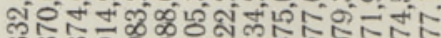
$\infty \infty \infty \pi)$

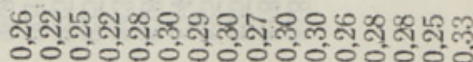

$0, \infty \infty m,=0,40,0,0, \infty$

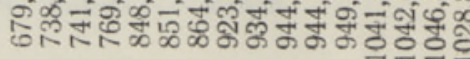

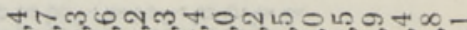

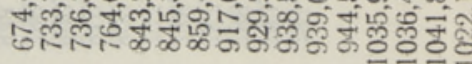

$3=0.010$

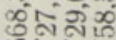

DNR

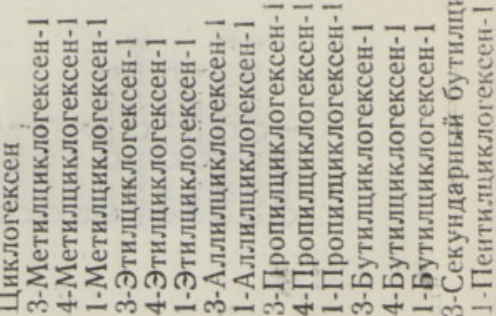


таблица 4

Индексы удерживания для алкенов на капиллярной колонке с полиэтиленгликолем 4000

\begin{tabular}{|c|c|c|c|c|c|c|c|}
\hline \multirow{2}{*}{ Алкены } & \multicolumn{6}{|c|}{ Температура колонки, ${ }^{\circ} \mathrm{C}$} & \multirow{2}{*}{$\delta I /{ }^{\circ} \mathrm{C}$} \\
\hline & 50 & 60 & 70 & 80 & 100 & 120 & \\
\hline $\begin{array}{l}\text { Гексен-1 } \\
\text { транс-Гексен-3 } \\
\text { цис-Гексен-3 } \\
\text { транс-Гексен-2 } \\
\text { цис-Гексен-2 }\end{array}$ & $\begin{array}{l}648,5 \\
656,4 \\
660,1 \\
663,4 \\
679,8\end{array}$ & $\begin{array}{l}648,7 \\
655,6 \\
660,1 \\
663,4 \\
680,5\end{array}$ & & & 的 & & $\begin{array}{c}0,02 \\
-0,08 \\
\bullet, 0 \\
0,0 \\
0,07\end{array}$ \\
\hline $\begin{array}{l}\text { Гептен-1 } \\
\text { транс-Гептен-3 } \\
\text { цис-Гептен-3 } \\
\text { транс-Гептен-2 } \\
\text { цис-Гептен-2 }\end{array}$ & $\begin{array}{l}747,7 \\
747,7 \\
756,2 \\
763,8 \\
778,9\end{array}$ & $\begin{array}{l}747,3 \\
746,4 \\
756,7 \\
764,5 \\
778,7\end{array}$ & & $\begin{array}{l}749,0 \\
749,0 \\
760,3 \\
766,9 \\
783,8\end{array}$ & & & $\begin{array}{l}0,03 \\
0,0 \\
0,12 \\
0,10 \\
0,12\end{array}$ \\
\hline $\begin{array}{l}\text { Октен-1 } \\
\text { транс-Октен-4 } \\
\text { транс-Октен-3 } \\
\text { цис-Октен-4 } \\
\text { цис-Октен-3 } \\
\text { транс-Октен-2 } \\
\text { цис-Октен-2 }\end{array}$ & & $\begin{array}{l}847,4 \\
839,3 \\
847,3 \\
851,9 \\
853,9 \\
864,3 \\
877,5\end{array}$ & $\begin{array}{l}847,2 \\
839,0 \\
847,2 \\
852,7 \\
854,0 \\
864,0 \\
877,5 \\
\end{array}$ & $\begin{array}{l}849,9 \\
841,9 \\
849,9 \\
858,1 \\
866,5 \\
881,5 \\
\end{array}$ & $\begin{array}{l}848,5 \\
840,1 \\
851,3 \\
856,6 \\
859,4 \\
865,7 \\
882,1 \\
\end{array}$ & & $\begin{array}{l}0,06 \\
0,06 \\
0,10 \\
0,09 \\
0,18 \\
0,07 \\
0,14 \\
\end{array}$ \\
\hline $\begin{array}{l}\text { Нонен-1 } \\
\text { транс-Нонен-4 } \\
\text { транс-Нонен-3 } \\
\text { цис-Нонен-4 } \\
\text { цис-Нонен-3 } \\
\text { транс-Нонен-2 } \\
\text { цис-Нонен-2 }\end{array}$ & & & $\begin{array}{l}947,7 \\
939,2 \\
945,8 \\
948,5 \\
952,2 \\
963,2 \\
976,7\end{array}$ & $\begin{array}{l}950,5 \\
941,2 \\
947,5 \\
951,8 \\
955,3 \\
964,8 \\
979,7 \\
\end{array}$ & $\begin{array}{l}949,8 \\
940,7 \\
946,5 \\
952,0 \\
954,8 \\
964,7 \\
980,0 \\
\end{array}$ & & $\begin{array}{l}0,12 \\
0,09 \\
0,06 \\
0,16 \\
0,14 \\
0,08 \\
0,16\end{array}$ \\
\hline $\begin{array}{l}\text { Децен-1 } \\
\text { транс-Децен-4 } \\
\text { транс-Децен-5 } \\
\text { тран-Децен-3 } \\
\text { цис-Децен-5 } \\
\text { цис-Децен-4 } \\
\text { цис-Децен-3 } \\
\text { транс-Децен-2 } \\
\text { цис-Децен-2 }\end{array}$ & & & $\begin{array}{l}1048,5 \\
1037,3 \\
1038,7 \\
1043,9 \\
1041,9 \\
1044,2 \\
1049,5 \\
1062,0 \\
1073,7\end{array}$ & $\begin{array}{l}1049,8 \\
1038,8 \\
1040,4 \\
1044,9 \\
\\
1045,9 \\
1051,9 \\
1064,1 \\
1077,9 \\
\end{array}$ & $\begin{array}{l}1051,7 \\
1039,2 \\
1040,7 \\
1046,2 \\
1047,0 \\
1050,3 \\
1053,9 \\
1065,3 \\
1080,7\end{array}$ & $\begin{array}{l}1055,3 \\
1040,3 \\
1042,6 \\
1046,4 \\
1047,7 \\
1052,2 \\
1056,0 \\
1066,3 \\
1084,0\end{array}$ & $\begin{array}{l}0,14 \\
0,08 \\
0,09 \\
0,06 \\
0,08 \\
0,16 \\
0,16 \\
0,11 \\
0,24 \\
\end{array}$ \\
\hline 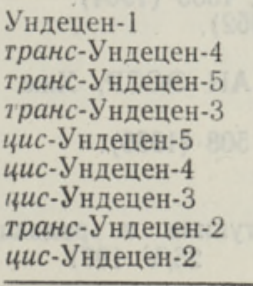 & & & & $\begin{array}{l}1148,4 \\
1137,7 \\
1137,7 \\
1145,5 \\
1142,1 \\
1145,6 \\
1151,7 \\
1161,1 \\
1176,4\end{array}$ & $\begin{array}{l}1151,2 \\
1136,9 \\
1138,7 \\
1145,7 \\
1143,4 \\
1145,8 \\
1151,8 \\
1163,8 \\
1179,3\end{array}$ & $\begin{array}{l}1153,6 \\
1139,3 \\
1139,7 \\
1146,7 \\
1146,9 \\
1149,6 \\
1154,5 \\
1166,5 \\
1183,0\end{array}$ & $\begin{array}{l}0,13 \\
0,08 \\
0,05 \\
0,03 \\
0,12 \\
0,10 \\
0,07 \\
0,14 \\
0,17\end{array}$ \\
\hline $\begin{array}{l}\text { Додецен-1 } \\
\text { транс-Додецен-6 } \\
\text { транс-Додецен-4 } \\
\text { транс-Додецен-5 } \\
\text { транс-Додещен-3 } \\
\text { чис-Додецен-6 } \\
\text { цис-Додецен-5 } \\
\text { чис-Додецен-4 } \\
\text { чис-Додецен-3 } \\
\text { транс-Додецен-2 } \\
\text { чис-Додецен-2 }\end{array}$ & $x=$ & & 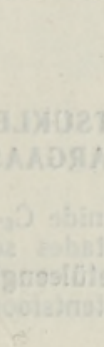 & ¿ & $\begin{array}{l}1252,8 \\
1235,9 \\
1236,9 \\
1239,4 \\
1239,8 \\
1243,1 \\
1247,3 \\
1254,1 \\
1266,5 \\
1281,5\end{array}$ & $\begin{array}{l}1254,9 \\
1237,6 \\
1238,4 \\
1239,8 \\
1243,7 \\
1244,3 \\
1248,8 \\
1255,7 \\
1267,5 \\
1283,3\end{array}$ & $\begin{array}{l}0,20 \\
0,06 \\
0,08 \\
0,08 \\
0,05 \\
0,09\end{array}$ \\
\hline
\end{tabular}




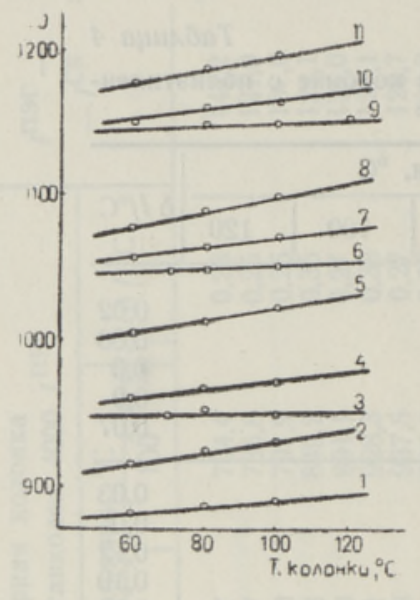

Рис. 4. Зависимость индексов удерживания от темпе ратуры колонки (жидкая фаза - полиэтиленгликоль 4000).

I - октен-1, 2 - 1-метилциклогексен-1, 3 - нонен-1, 4 - 1-про пилциклопентен-1, $5-1$-этилциклогексен-1, $6-$ децен-1, 7 1-бутилциклопентен-1, 8 - 1-пропилциклогексен-1, 9 - ундецен-1 $10-1$-пентилциклопентен-1, $11-1$-бутилциклогексен-1.

живания $\delta I /{ }^{\circ} \mathrm{C}$ для алкенов и цикленов, которые относятся к изменению температуры на $1{ }^{\circ} \mathrm{C}$.

На рис. 4 приведены графики в координатах $I-t$ для 1 -алкенов, 1 -алкилциклопентенов и 1-алкилциклогексенов. Как видно из табл. и рис. 4, температурная зависимость индексов удерживания у алкенов невелика $\left(\delta I /{ }^{\circ} \mathrm{C}=\right.$ $=0,03 \div 0,2)$.

Таблица 5

$\delta I /{ }^{\circ} \mathrm{C}$ для цикленов

\begin{tabular}{l|c|c}
\hline Циклены & $\begin{array}{c}\text { Капиллярная колонка } \\
\text { со скваланом }\end{array}$ & $\begin{array}{c}\text { Капиллярная колонка с } \\
\text { ПЭГ 4000 }\end{array}$ \\
\hline Циклопентены & $0,08-0,22$ & $0,25-0,44$ \\
Циклогексены & $0,22-0,32$ & $0,42-0,55$
\end{tabular}

Для цикленов зависимость индексов удерживания от температуры значительно бо́льшая, чем для алкенов $\left(\max \delta I /{ }^{\circ} \mathrm{C}=0,55\right.$ ед.). Индексы удерживания у цикленов на капиллярной колонке с полиэтиленгликолем 4000 возрастают с повышением температуры значительнее, чем на колонке со скваланом (табл. 5).

\section{ЛИТЕРА ТУ РА}

1. W a 11 a r d B., Chim. et ind.-Gen. Chim., 103, Nr. 16, 2042 (1970) .

2. Et tre L. S., B ill e b K., J. Chromatogr., 30, Nr. 1, 1 (1967).

3. Erde y L., T a k a c s J., S z a l a n e ry E., J. Chromatogr., 46, Nr. 1, 29 (1970).

4. Hively R. A., H i n t o n R. E., J. Gas Chromatogr., 6, Nr. 4, 203 (1968).

5. A sing er F., Fell B., S te f f a n G., Chem. Ber., 97, Nr. 6, 1555 (1964).

6. L i n d I a r H., Helv. Chim. Acta, 35, Fasc. II, Nr. 57, 446 (1952).

7. B a il e y W. J., Jacs., 81, Nr. 3, 651 (1959).

8. Эйзен Ю., 'Р анг С., К К ск В., Эйзен О., Изв. АН ЭССР, Хим. І'еол, 16, 101 (1967).

9. Gil-Av E., Heri ing J., Sh a b ta i J., J. Chromatogr., 1, 508 (1958).

10. Kov a ts E., Helv. Chim. Acta, 41, 1915 (1958).

Ннститут химии

Академии наук Эстонской ССР
Поступила в редакцию 26/V 1971

\section{ANNE ORAV, O. EISEN}

\section{ALKEENIDE, ALKUUNIDE JA TSUKLEENIDE RETENTSIOONIINDEKSITE MÄARAMINE KAPILLAARGAASIKROMATOGRAAFIA ABIL}

Määrati $n$-alkeenide $\mathrm{C}_{6}-\mathrm{C}_{12}$, alküünide $\mathrm{C}_{6}-\mathrm{C}_{9}$ ja tsüklopenteenide ning tsüklohekseenide $\mathrm{C}_{5}-\mathrm{C}_{11}$ retentsiooniindeksid, kasutades selleks kolme erineva polaarsusega vedelat faasi (skvalaan, polüfenüüleeter ja polüetüleenglükool 4000) sisaldavat kapillaarkolonni.

Uuriti $n$-alkeenide ja tsükleenide retentsiooniindeksite sōltuvust kolonni temperatuurist, 
ANNE ORAV, O. EISEN

\section{THE RETENTION INDEXES FOR ALKENES, ALKYNES AND CYCLENES ON CAPILLARY COLUMNS}

The retention indexes for $n$-alkenes $C_{6}-C_{12}$, alkynes $C_{6}-C_{9}$, cyclopentenes and cyclohexenes $C_{5}-C_{11}$ have been determined, using capillary columns with squalane, poly. phenylene ether and polyethylene glycol 4000.

The dependence of retention indexes on temperature has been investigated. 